\title{
Natural silicon carbide from different geological settings: polytypes, trace elements, inclusions
}

\author{
Andrei A. Shiryaev ${ }^{1}$, William L. Griffin ${ }^{2}$, Emil Stoyanov ${ }^{3,4}$, Hiroyuki Kagi ${ }^{5}$ \\ ${ }^{I}$ Institute of Crystallography, Moscow, Russia \\ ${ }^{2}$ GEMOC, Sydney, Australia \\ ${ }^{3}$ Bayerisches Geoinstitute, Bayreuth, Germany \\ ${ }^{4}$ Arizona State University, Tempe, USA \\ ${ }^{5}$ Tokyo University, Japan
}

Silicon carbide is a material of significant interest for various fundamental and applied fields: from highpower electronics to crystallography and the oxidation state of Earth's mantle. Since the stability of SiC requires extremely low $\mathrm{fO}_{2}$ values, some geologists consider moissanite as a "geological aberration". However, a growing body of data confirms the rather widespread existence of small $\mathrm{SiC}$ grains in various geological settings. Moissanite has been found not only in mantle derived rocks (e.g., kimberlites, diamonds), but also in high- and low-grade metamorphic rocks, limestones and pegmatites (for a review see Derkachenko et al., 1972, Lyakhovich, 1980, Marshintsev, 1990). SiC is also reported in meteorites and interstellar dust. Interestingly, isotopic analyses show that $\mathrm{SiC}$ is always enriched in ${ }^{12} \mathrm{C}$ (Marshintsev, 1990, Mathez et al., 1995). The genesis of natural SiC remains a matter of debate.

In this work we report results of a detailed investigation by complementary techniques of natural $\mathrm{SiC}$ grains recovered from two contrasting geological settings: 1) from the heavy fraction of the Mir kimberlite pipe (Yakutia), and 2) from Triassic limestones in Bulgaria. Structural perfection, major and trace element chemistry of natural $\mathrm{SiC}$ grains and description of inclusions of other phases are presented.

\section{Samples and methods}

Issues of contamination were carefully addressed during extraction of kimberlitic $\mathrm{SiC}$ and the contamination is completely excluded in the case of Bulgarian samples. The rocks containing the latter set of $\mathrm{SiC}$ grains were collected at the geographical location and from strata described as moissanitebearing by Gnoevaja and Grozdanov (1965). They were recovered from the heavy fraction of the acidresistant residue of these rocks, containing wellpreserved Triassic fossils. Note, that the $\mathrm{SiC}$ grains are genetically unrelated to the host limestones.

The kimberlitic moissanite grains $(n=106)$ are up to 1 $\mathrm{mm}$ across and the Bulgarian grains $(n=22)$ are less than 100 microns. The grains are usually transparent and show various colors, but usually are bluish-green. Similar to earlier observations (Derkachenko et al., 1972, Marshintsev, 1990) most grains are fractured, but some sides preserve well-formed crystallographic faces.

Raman microspectroscopy was employed to determine the polytypes, to assess degree of crystalline perfection, and to identify of some inclusions. Major and trace elements in $\mathrm{SiC}$ bulk and in inclusions exposed by polishing were measured using Electron Microprobe (EMP) and by LAM-ICP-MS. For comparative purposes we studied synthetic $\mathrm{SiC}$ samples produced by very different methods: the Acheson and the modified Lely (sublimation) methods. The SiC grains were cast in epoxy and polished prior to analyses. Transmission Electron Microscopy (TEM) was used for direct investigation of submicroscopic inclusions. Loose grains were mechanically crushed and suspension brought to the $\mathrm{Cu}$ grid.

\section{Results}

Raman spectroscopy

Due to differences in band gap the color of $\mathrm{SiC}$ is polytype-dependent. Therefore, already from optical examination the majority of natural $\mathrm{SiC}$ grains are identified as the $6 \mathrm{H}$ variety. However, doping strongly influences $\mathrm{SiC}$ coloration and a more reliable method should be employed to identify the polytypes. Raman spectroscopy is a powerful tool to identify $\mathrm{SiC}$ polytypes and to assess degree of lattice disorder (Nakashima and Harita, 1997). Typical spectra are shown in Fig. 1. Grains of pure $6 \mathrm{H} \mathrm{SiC}$ make $55 \%$ of both samples sets. The second most abundant pure polytype is $15 \mathrm{R}$ : $8 \%$ of the kimberlitic population (pure $15 \mathrm{R}$ is not present in the more limited Bulgarian set). Some other grains show the presence of $6 \mathrm{H}+15 \mathrm{R}$ mixtures in different proportions. In total the grains made of pure or intermixed $6 \mathrm{H}$ and $15 \mathrm{R}$ polytypes make up $83 \%(73 \%)$ of kimberlitic (Bulgarian) sets. It is well-known that the $6 \mathrm{H}$ and $15 \mathrm{R}$ polytypes generally form at temperatures exceeding $1300^{\circ} \mathrm{C}$. Several grains $(\sim 5 \%)$ contain mixtures of $6 \mathrm{H}$ and $4 \mathrm{H}$ polytypes. The rest of the studied populations consist of various mixtures of $6 \mathrm{H}, 8 \mathrm{H}, 15 \mathrm{R}$ and $21 \mathrm{R}$ polytypes; such crystals may be thought of as containing long-period polytypes. As is known, disorder in $\mathrm{SiC}$ is not completely random and disordered regions consist of mixtures of randomly disordered simple polytype 
domains and those containing stacking faults distributed periodically or near-periodically. Some of the grains $(\sim 10 \%)$ show extremely complex spectra clearly indicating heavily disordered structures.

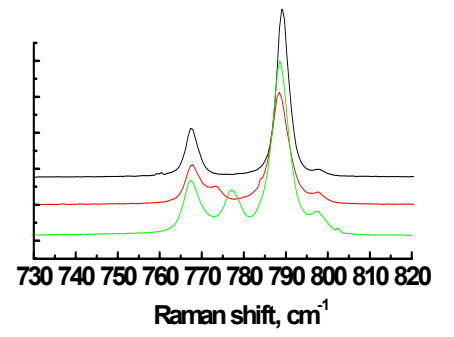

Fig. 1. Parts of the Raman spectra (TO modes) of $\mathrm{SiC}$ grains with various degree of perfection (disorder increases from top to bottom).

The shape and position of the LO phonon mode of SiC provides information about stresses and concentration of charge carriers. Only few spectra of the studied grains show stress-related features. At the same time, many grains show the presence of various levels of uncompensated charge carriers (presumably $\mathrm{Al}$, B, perhaps $\mathrm{N}$, see below), whose concentrations reach several hundred ppm in some grains. On average, the $15 \mathrm{R}$ grains contain higher concentrations of uncompensated impurities than the $6 \mathrm{H}$ ones. The Bulgarian set is, on average, also richer in dopants in comparison with the kimberlitic set.

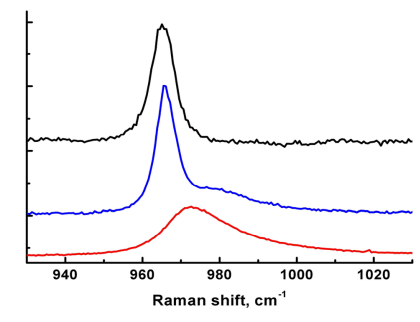

Fig. 2. LO phonon of SiC. Concentration of uncompensated dopants increases from top to bottom. The middle curve shows superposition of two domains.

The LO peak of some grains clearly reflects the superposition of at least two components (fig. 2). This suggests the existence of domains with markedly different type and/or concentration of uncompensated dopants. Judging from the size of the laser spot this heterogeneity is present at a scale of $<10$ microns. Cathodoluminescence images (Fig. 3) confirm the existence of such zoning. Recently Shiryaev et al., (2008) reported C and Si isotopic zoning in some of the grains.

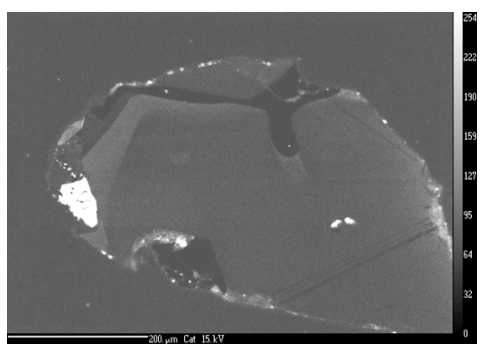

Figure

Cathodoluminescenc e of one of $\mathrm{SiC}$ grains showing growth(?) zoning and inclusions of $\mathrm{Si}$.

Several grains (though the statistics are limited) show features in the $\mathrm{OH}$ vibrations region (fig. 4). However, it is not yet clear whether these bands are due to structural defects such as $\mathrm{C}-\mathrm{H}$ complexes in $\mathrm{SiC}$ matrix or are due to microscopic H-rich inclusions.

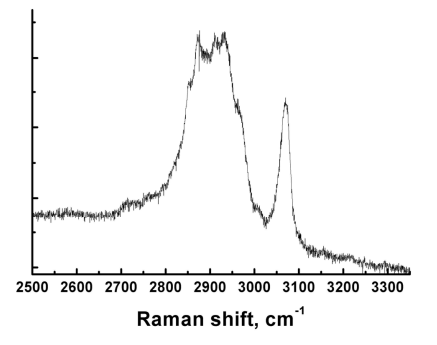

Fig. 4. H-related bands in Raman spectrum on a Yakutian SiC grain.

\section{Major and trace elements}

Moissanite grains are typically quite pure $\mathrm{SiC}$ with small admixture of oxygen (0.1-0.3 wt \%). In the synthetic samples only Al, B, Ti, V, Sc were observed. These impurities (also N) are typical of synthetic SiC. Concentrations of these elements are roughly similar in synthetic and natural samples studied. However, the trace element chemistry of natural $\mathrm{SiC}$ is much richer than that of synthetic SiC samples. The most plausible explanation of chemical differences between natural and synthetic materials lies in amount of submicroscopic accessory phases. The SiC lattice is similar to diamond in its extremely low capacity for impurities except some subsitutional elements (Al, N, $\mathrm{B})$. Therefore, it is believed that most trace elements are present in unresolved syngenetic inclusions and not in the $\mathrm{SiC}$ crystalline lattice. The contents of most trace elements in studied natural SiC grains are low (1-200 ppm), but several important conclusions can be drawn from the chondrite-normalised patterns.

- $\mathrm{Al}$ contents show a wide range, as do $\mathrm{Cr}$ and $\mathrm{Ni}$;

- The contents of several chalcophile elements $(\mathrm{Cu}$, $\mathrm{Zn}, \mathrm{Mo}$ ) are high compared to $\mathrm{Ni}$, suggesting that no sulfide phase coexisted with the $\mathrm{SiC}$;

- REE contents rise weakly from HREE to MREE, but decline on average from $\mathrm{Nd}$ to $\mathrm{La}$;

- Sr shows a pronounced negative anomaly relative to $\mathrm{Nd}$ and $\mathrm{Sm}$, and $\mathrm{Y}$ shows a negative anomaly relative to Dy and Ho; these features are also characteristic of trace elements in diamonds;

- Eu shows no anomaly relative to $\mathrm{Sm}$ and $\mathrm{Gd}$;

- Contents of Sn are high and relatively constant;

- $\mathrm{Zr} / \mathrm{Hf}$ is strongly subchondritic; limited data suggest the same is true of $\mathrm{Nb} / \mathrm{Ta}$; again, these features are characteristic of diamond trace-element patterns.

Several SiC grains from both localities contain inclusions of other phases. The most common is silicon metal, followed by an iron silicide $\left(\mathrm{FeSi}_{2}\right)$ and an oxygen-bearing $\mathrm{Si}(\mathrm{C}, \mathrm{O})$ phase. Intergrowths of these phases in several grains indicate that they form a single primary assemblage. Raman spectroscopy provides unambiguous confirmation of presence of metallic Si. A slight shift of the Si Raman peak indicates residual pressure of several kbars. The presence of Si metal and various silicides in natural $\mathrm{SiC}$ was reported previously (Gnoevaja and Grozdanov 1965, DiPierro et al., 2003, Lyakhovich, 1980, Marshintsev 1990, Mathez et al., 1995). However, the chemical composition and crystal chemistry of previously reported compounds differ from our observations. 
A BSE image of an inclusion-bearing kimberlitic $\mathrm{SiC}$ grain is shown in fig. 5 (see also Fig. 3). A semieuhedral crystal of $\mathrm{SiC}(150 \times 350 \mu \mathrm{m})$ contains three inclusions with negative-crystal forms; each consists of $\mathrm{Si}^{0}$ with blebs of $\mathrm{FeSi}_{2}$ nucleated along the contacts. At the top of the grain, a large irregular grain of $\mathrm{FeSi}_{2}$ is surrounded by a halo of cauliflower-shaped $\mathrm{SiC}$ grains set in a matrix of $\mathrm{SiO}_{2}$. The $\mathrm{SiO}_{2}$ also forms botryoidal outgrowths along the edge of the $\mathrm{SiC}$ crystal.

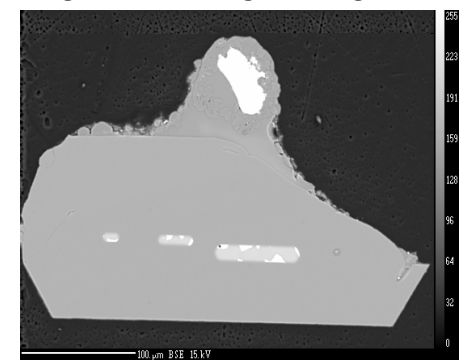

Figure 5. BSE image of inclusion-rich kimberlitic $\quad \mathrm{SiC}$ grain.

The large $\mathrm{FeSi}_{2}$ grain has a complex internal structure, with anastomosing "worms" of metallic Ti set in the $\mathrm{FeSi}_{2}$ matrix (not shown); the microstructure strongly suggests exsolution of the $\mathrm{Ti}^{0}$ from the $\mathrm{FeSi}_{2}$, and the presence of subgrains within the $\mathrm{FeSi}_{2}$. The $\mathrm{Ti}^{0}$ strongly concentrates $\mathrm{Ni}$ and $\mathrm{Mn}$.

The complex intergrowth of $\mathrm{SiC}$ and $\mathrm{SiO}_{2}$ around the $\mathrm{FeSi}_{2}$ grain suggests a secondary replacement process, which may have oxidised $\mathrm{Si}^{0}$ and, to some extent, $\mathrm{SiC}$. The relationships between the phases in these complex grains suggest that $\mathrm{SiC}$ coexisted with a melt phase dominated by $\mathrm{Si}^{0}$ and $\mathrm{Fe}^{0}$; this melt was trapped as inclusions in the $\mathrm{SiC}$ and formed a grain-boundary phase. On cooling, $\mathrm{FeSi}_{2}$ appears to have crystallised (exsolved?) from the $\mathrm{Si}^{0}$, typically along contacts with $\mathrm{SiC}$. This relationship between $\mathrm{Si}$ and $\mathrm{FeSi}_{2}$ makes trace element analysis of $\mathrm{Si}$ problematic due to contamination by microscopic silicide inclusions.

The TEM study shows presence of submicroscopic $\mathrm{FeSi}_{2}$ inclusions dispersed in the $\mathrm{SiC}$ matrix (fig. 6) Electron diffraction confirms identification of the phase as a $\mathrm{FeSi}_{2}$-based solid solution. Presumably, deviations of the composition from an ideal formula lead to absence of characteristic Raman signal.
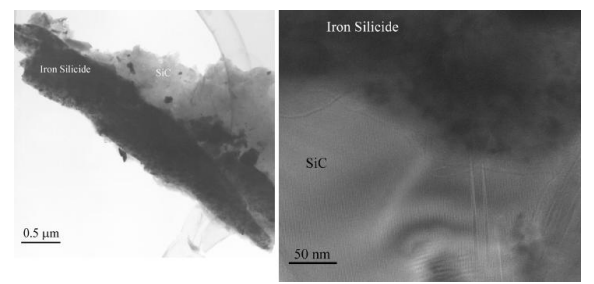

Figure 6. TEM image of $\mathrm{FeSi}_{2}$ inclusion in a Bulgarian $\mathrm{SiC}$.

Iron Silicide is compositionally variable: Fe ranges from 43.6-46.3 wt\% (mean 45.4); Si from 49.2-55.4 $\mathrm{wt} \%$ (mean 50.8). Ti varies widely; the mean value is $2.0 \mathrm{wt} \%$, but many grains contain $2.5-3.8 \mathrm{wt} \% \mathrm{Ti}$, while others contain $<0.3 \mathrm{wt} \%$. Ni varies from $0.04-$ $0.33 \%$, and $\mathrm{Mn}$ from $0.03-1.3 \mathrm{wt} \%$. The calculated structural formula is $(\mathrm{Fe}, \mathrm{Ti}, \mathrm{Mn}, \mathrm{Cr}, \mathrm{Ni}) \mathrm{Si}_{2}$. This is clearly different from the $\mathrm{Fe}_{3} \mathrm{Si}_{7}$ composition reported as inclusions in moissanite by DiPietro et al. (2003).

The $\mathrm{FeSi}_{2}$ phase has high contents of many trace elements; it appears to concentrate most of these elements in the system, and thus may give an indication of the nature of the environment in which the $\mathrm{SiC}$ and its associated phases formed. The key observations from the chondrite-normalised traceelement patterns are:

- High levels of elements such as Al, Cr, Mn, Fe;

- High levels of chalcophile elements, again indicating that no sulfide phase was present;

- A steep increase in REE contents from $\mathrm{Lu}$ to $\mathrm{Ce}$, but chondritic (on average) $\mathrm{La} / \mathrm{Pr}$; Ba levels are low relative to $\mathrm{La}$;

- A striking negative $\mathrm{Eu}$ anomaly; $\mathrm{Eu}$ is below detection limits in all analyses, even those with several hundred ppm of $\mathrm{Nd}$ and $\mathrm{Gd}$;

- Smaller, but still marked, negative anomalies in Sm and $\mathrm{Yb}$ (as well as $\mathrm{Y}$ );

- High levels of Sn, as noted in the SiC;

- $\mathrm{Zr} / \mathrm{Hf}$ ranges from subchondritic in some grains to suprachondritic in others; $\mathrm{Nb} / \mathrm{Ta}$ is generally subchondritic.

The $\mathrm{FeSi}_{2}$ phase clearly accepts highly charged, small ions (e.g., REE and HFSE). The REE pattern of the $\mathrm{FeSi}_{2}$ suggests that nearly all $\mathrm{Eu}$, and much of the $\mathrm{Sm}$, has been reduced to the $2+$ state and entered another phase. The lack of $\mathrm{Eu}$ and $\mathrm{Sm}$ anomalies in the moissanite suggests that the $\mathrm{SiC}$ does not discriminate against $\mathrm{Eu}^{2+}$ or $\mathrm{Sm}^{2+}$. Without samples of other coexisting phases, it is not clear where the Eu and Sm are concentrated in this environment.

The Si-C-O phase contains 55-56\% Si, 9.6-12.0 wt\% $\mathrm{O}$; we assume that the balance is made up of $\mathrm{C}$. The stoichiometry of this phase appears to be close to $\mathrm{Si}_{4}(\mathrm{C}, \mathrm{O})_{7}$, which would require a mixed valence (between 3 and 4) for Si.

The present study suggests that formation of natural $\mathrm{SiC}$ was related to the cooling of Fe-Al-Si-C melt. However, the geochemical environment of its genesis remains unclear.

\section{References}

Derkachenko L.I., Zaretskaya G.M., Obuhov A.P., Sokolova T.V., Filonenko N.E., (1972) Mineralogy of silicon carbide, "Nauka," Leningrag (in Russian).

DiPierro S., Gnos E., Grobety B.H., Armbruster T., Bernasconi S.M., and Ulmer P., (2003) American Mineralogist, 88 1817-1821.

Gnoevaja N., Grozdanov L., Moissanite from Triassic rocks, NW Bulgaria (1965), Proceedings of Bulgarian Geological Society, 26, 89-95.

Lyakhovich, V.V. (1980) Origin of accessory moissanite. International Geology Review, 22, 961-970.

Marshintsev V.K., (1990) Natural silicon carbide in Yakutian kimberlites. Mineralogicheskii Zhurnal 12 17-26 (in Russian).

Mathez E.A., Fogel R.A., Hutcheon I.D., Marshintsev V.K., (1995) Geochimica et Cosmochimica Acta 59 781-791.

Nakashima S., Harita H., (1997) Raman investigation of SiC polytypes. Physica Status Solidi A162 39-64.

Shiryaev A.A., Wiedenbeck M., Reutsky V., Polyakov V.B., Mel'nik N.N., Lebedev A.A., Yakimova R., (2008) Isotopic heterogeneity in synthetic and natural silicon carbide. Journal of Physics and Chemistry of Solids, in press, doi:10.1016/j.jpcs.2008.05.005 